\title{
The ecological efficiency assessment in the system of management
}

\author{
Boris Khrustalev ${ }^{1, *}$, Natalya Smolich ${ }^{2}$, Svetlana Barbashova $^{3}$ and Olga Burmistrova $^{3}$ \\ ${ }^{1}$ Penza State University of Architecture and Construction, 440028, Titov St., 28, Penza, Russia \\ ${ }^{2}$ Moscow State University of technologies and management, 440026, Volodarskogo st., 6, Penza, \\ Russia \\ ${ }^{3}$ Financial University under the Government of the Russian Federation, 440052, Kalinin st., 33-B, \\ Penza, Russia
}

\begin{abstract}
The article presents models and methods of environmental efficiency assessment. The analysis of methodological approaches to environmental efficiency assessment has been carried out. The research concludes that the indicators of ecological management benefit and costs and nature protection activity are key criteria in environmental efficiency estimation.
\end{abstract}

\section{Introduction}

Ecological management is one of the perspective spheres of management activity of the organizations which is based on the nature protection activity that aims at providing environmental safety and environmental protection. The systematics and effectiveness are considered to be distinctive features of ecological management in comparison with the present management of nature protection activity. The System of Ecological Management (SEM) presents one of the forms which introduces methods of ecological management to the administrative management system. The requirements to SEM are regulated by the international and national the Russian State Standard (GOST R ISO standard 14001-2016) [1] which acts as a criterion when the certified audit is made. The assessment of environmental efficiency is a compulsory procedure in functioning of SEM.

\section{Problem statement and research}

The concept of environmental efficiency and instruments of its realization were worked out for the developed and welfare states of the West, which made great progress in the solution of the economic and social problems as the countries possess resources for the solution of environmental protection problems [2]. These counties are characterized by effective ecological legislation system; there are high taxes on environmental pollution, the high prices of the imported raw material resources, which, in general, creates good prerequisites for the development of programs which point at the increase in environmental efficiency.

\footnotetext{
${ }^{*}$ Corresponding author: angela-1309.m@yandex.ru
} 
In developing countries and countries with transitional economy, the ecological expenses of the enterprises-pollutants are, as a rule, small even at the high level of pollution, and the accepted amount of ecological payments is inadequate in comparison with the caused ecological damage. There is a point of view that the principles and mechanisms of environmental efficiency will not start working in these countries, which Russia belongs to as well. This results from the fact that great costs and a basic change of the ecological rationing procedure will be involved in the prevention of environmental pollution. And at the constant deficiency of means and insufficiency of real support from the state, problems of environmental efficiency will not be resolved. Talking about the present moment, it should be noted that implementation of programmes for the increase in environmental efficiency demands not only on capital investments, but, first of all, on the expert decisions. Even the company with high ecological expenses could be not at all ecologically effective. For example, its efforts can be concentrated only on technologies of emission cleaning at the end of a tube. The adoption of more justified decisions is promoted by availability of objective information which can be obtained by means of such management instruments as the assessment of environmental efficiency.

For the last three-four years a number of the organizations of the Penza region realized a need in the development of the tool assessment of environmental efficiency, relying on the scientific potential of higher educational institutions [3].

The analysis of methodical approaches to the assessment of environmental efficiency has showed that there were basic changes in methodology and models of environmental efficiency assessment from 1980 till the present time.

The first model is economic (fig. 1). The "Temporary standard technique of implementation of nature protection actions and assessment of the economic damage caused to the national economy by environmental pollution" accepted in 1983 became a standard and methodical basis of the model. Nature protective actions are considered all types of economic activity directed to the decrease and elimination of some negative anthropogenic impacts on the environment, preservation, improvement and rational usage of natural resources potential. There were some construction activities and management of the clearing and neutralizing constructions and devices, development of low-waste and waste-free technological processes and productions, placement of the enterprises and the systems of transport traffic taking into account ecological requirements [4]. The estimation model of the result of nature protection actions has provided the calculation of an indicator of the overall (absolute) cost efficiency of $\mathrm{E}^{\mathrm{a}}$ and effectiveness ratio of capital investments in construction of $\mathrm{E}^{\mathrm{K}}$.

The indicator of the overall (absolute) cost efficiency of $\mathrm{E}^{\mathrm{a}}$ was defined as the relation of annual economic effect of nature protection actions to the expenses which have caused them. This indicator was used in the justification structure and volume of nature protection actions [5]. The effectiveness ratio of the capital investments in construction of $\mathrm{E}^{\mathrm{K}}$ was used for structure determination and volumes of capital investments of nature allotment.

The absolute advantage of this model was its novelty, attempts of result assessment from an ecological component activity of the organizations were made for the first time.

The most considerable drawback of this model should be considered as an artificial allocation of nature protection actions and delegation of responsibility for the result of their performance only to ecological services whose powers did not correspond to either the status, or the functions necessary for the realization of nature protection actions. In the model the principle of "the end of a tube" operating then in nature protection activity, that is a result assessment of nature protection actions is accurately traced. 


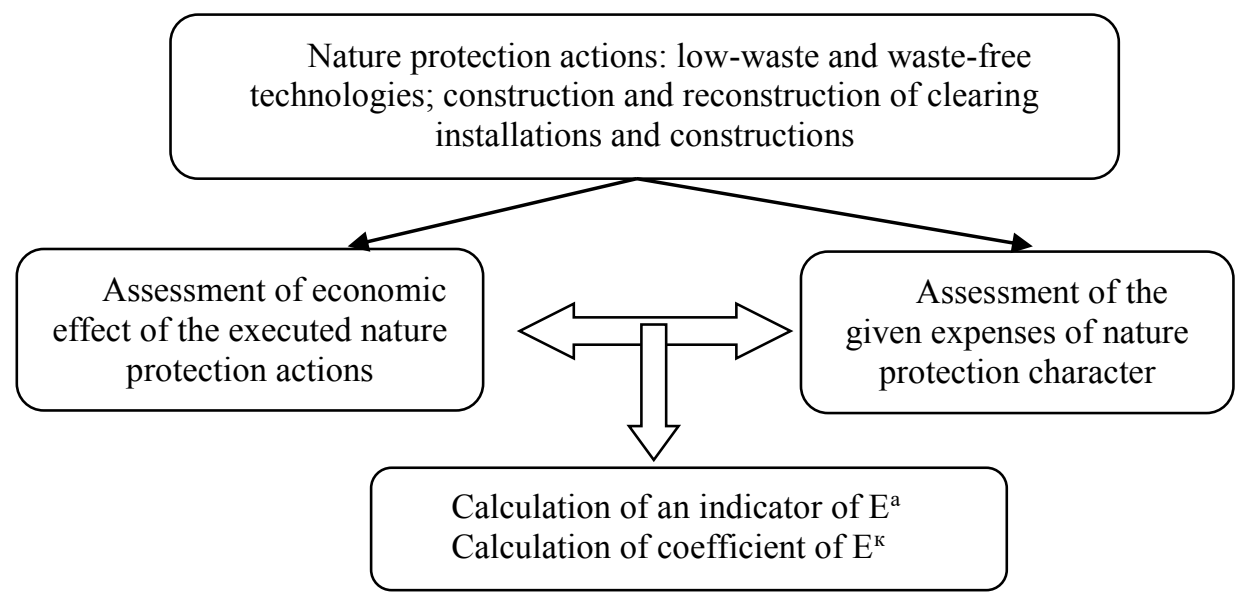

Fig. 1. Economic model of assessment of the result of nature protection actions.

Projected and planned complex of nature protection actions ideally had to provide:

- observance of the regulatory requirements to the quality of the environment which are equitable to the interests of health protection and protection of the environment taking into account the perspective changes which are caused by the development of production and demographic shifts;

- obtaining the maximum economic effect of the environmental improvement, saving and fuller usage of natural resources [6].

The following model is ecologo-social and economic (fig. 2). It included a complex result assessment of the performance of nature protection actions, namely:

1. The ecological result consists of a decrease of the negative impact on the environment and the improvement of its state and was shown in the reduction of pollution volumes which come in the environment or in the decrease of the environmental pollution level in general (concentration of harmful substances in the environment, noise levels, a radiation and so on), in increase in quantity and improvement of the quality suitable for usage land, forest, water resources, etc.

2. The social and economic result consists of the increase of standard of living of the population, efficiency of social production, an increase in a national wealth of the country. At the same time social results became apparent in the improvement of physical development of the population and in reduction of incidence, increase in a duration of life and the period of a person's activity, improvement of working conditions and rest, maintenance of ecological equilibrium (including preservation of a genetic fond), preservation of esthetic value of natural and anthropogenic landscapes, nature sanctuaries, reserved zones and other protected areas, in a creation of favourable conditions for the growth of creative potential of the personality and culture development, for improvement of moral consciousness of the person [7]. Social results, being presented in cash, received partial reflection in economic results of nature protection actions.

3. Economic results were concluded in economy and prevention of the natural resources loses, live and public work in productive and non-productive spheres and also in the sphere of personal consumption reached thanks to the implementation of nature protection actions.

At the economic justification of nature protection actions an integrated approach had to be observed that meant:

- fuller coverage of all social-economic consequences of various nature protection actions in different spheres, both in recent, and in more remote prospect; 
- fuller coverage of all expenses, the considered options of nature protection actions connected with implementation;

- accounting of a temporary factor at the expenses assessment and nature protection actions;

- the comprehensive analysis of justification of nature protection actions with the need of economy of the costs on the improvement of the state environment and ensuring more effective use of natural resources for scales of the considered organization, territories, etc. in general [8].

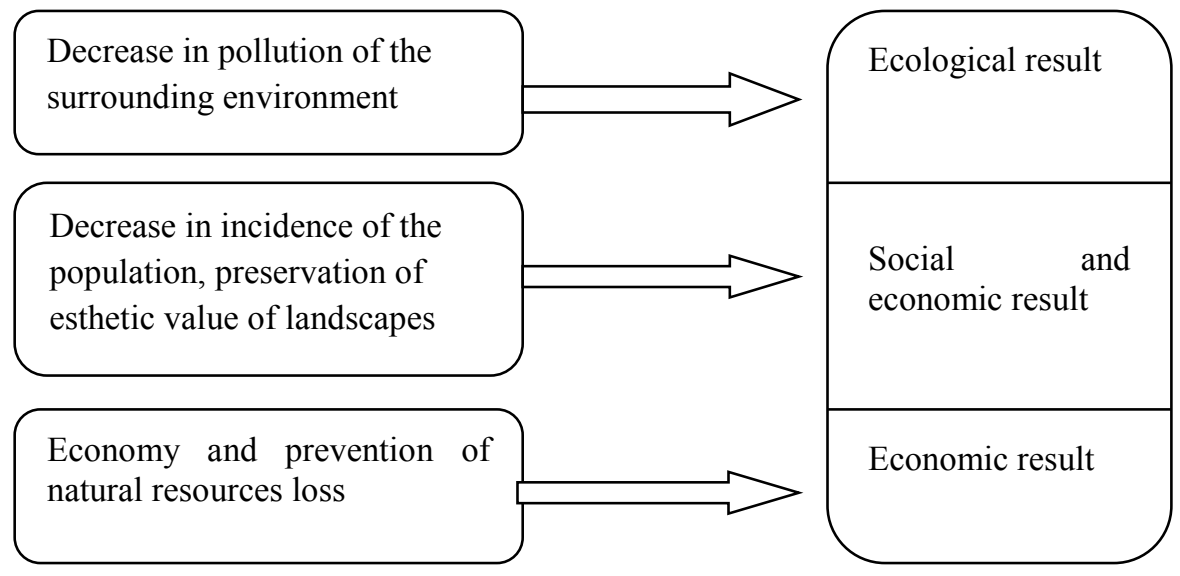

Fig. 2. Ecologo-social-economic model of result assessment of nature protection actions.

The main advantage of this model can be considered as its complexity, expansion of object base of effectiveness assessment of nature protection actions.

Shortcoming is considered to be the lack of methodical approaches and uniform indicators of assessment of social-economic and economic results, uncertainty of limits of responsibility for evaluating effectiveness of nature protection activity.

The modern model is the assessment of environmental efficiency (fig. 3) which has been developed due to the techniques of efficiency assessment of nature protection actions of the previous models and also requirements of the Russian State Standard (GOST P ISO 14031) [9]. The most significant in it is the prevention of environmental pollution as a result of the influence on the processes which caused it as the prime reason of the negative impact.

Standard and methodical base of this model is the international and national the Russian State Standard (GOST P ISO standard 14031-2016). The standard, besides accurate definitions to the main terms, provides the model of assessment and classification of indicators of environmental efficiency, the recommendation about the choice of these indicators depending on the estimation purposes [10].

Two categories of indicators for estimation are regulated: indicators of environmental efficiency and indicators of state of environment [11].

The indicator of environmental efficiency is a specific form of submission of information on environmental efficiency of the organization.

The indicator of state of environment is an indicator of the environment on local, regional, national or global scales [12].

Indicators of environmental efficiency, in turn, are subdivided into:

- the indicators of management efficiency of the organization providing information on the efforts made by the management for the purpose of impact on the environmental efficiency; 
- the indicators of efficiency of functioning of the organization providing information on environmental efficiency of functioning.

The central place in model is taken by determination of priority of ecological aspects of enterprise activity. This stage is a starting point to begin the process of estimation of environmental efficiency [13].

The advantage of this model is the existence of the methodical base which allows:

- operating priority ecological aspects;

- involving in the process of estimation of environmental efficiency not only ecological services, but also other functional services which participate in achievement of the chosen indicators of environmental efficiency and also various levels of management;

- accurately defining indicators of environmental efficiency for various services and estimations.

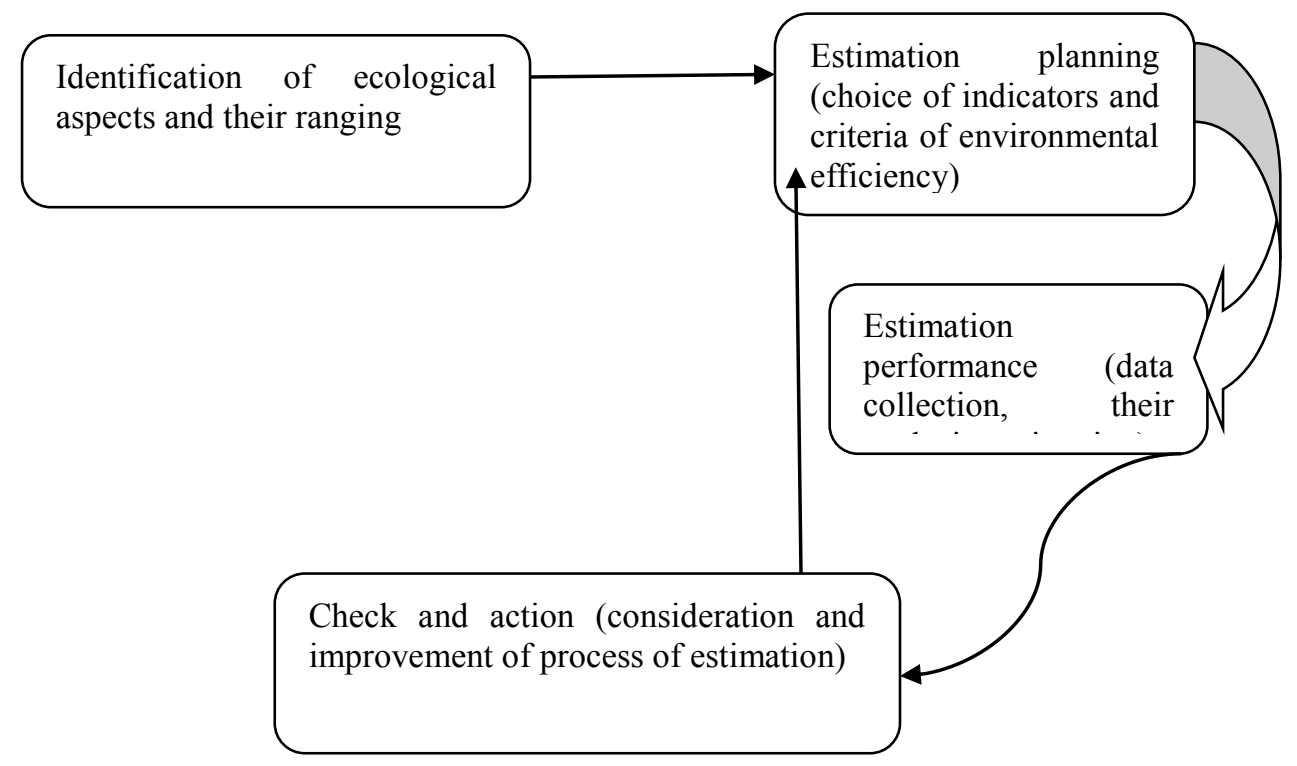

Fig. 3. Model of environmental efficiency assessment.

The lack of this model can be considered as a labour input in determination of the priority ecological aspects of activity of the enterprise [14].

One of key positions in assessment of environmental efficiency is the calculation of benefit and costs of ecological management and nature protection activity[15].

The benefit from ecological management and nature protection activity can be presented:

1. In the form of the economy reached as a result of reduction of the quantity of the used resources, prevention of pollution or a recycling of wastes.

2. In a type of income from selling of the new products which are turned out taking into account regulatory requirements on ensuring environmental safety (pays off by each type of products separately);

3. In a type of income, received from the organizations which carry out collecting of wastes, in case of increase in volumes caught (collected) and handed over to specialized organizations in wastes or at change of their qualitative structure.

4. In the form of savings from decrease or total absence of penalties for noncompliance with requirements of the federal ecological legislation and other regulations regarding environmental protection. 


\section{Conclusions}

Thus, the environmental efficiency should be an indicator of the assessment systems of ecological management and/or nature protection activity, be measured and served as a reliable criterion of making management decisions. At the same time, the indicators of benefits and costs of ecological management and nature protection activity are key criteria in the assessment of environmental efficiency.

\section{References}

1. Russian Federation Standard GOST R ISO 14001-2016

2. S.A. Barbashova, A.S. Chigrov, Innovations and Investments 1, 57-59(2013)

3. V.V. Bondarenko, Economy and society: problems and prospects of modernization in Russia 1, 383-398 (2013)

4. O.A. Burmistrova, N.V. Kirillova, O.A. Burmistrova, Collection of scientific papers of the VIII International Scientific and Practical Conference 1, 9-10 (2017)

5. P.G. Grabovoi, A.B. Kapustkina, Real Estate: Economics, Management 1, 70-77 (2015)

6. B.B. Khustalev, Iu.B. Khustalev, International Conference "Science and Education" 1, 52-60(2016)

7. V.A. Pukhkal, A.B. Mottaeva, Magazine of Civil Engineering 81(5), 203-212 (2018) doi: 10.18720/MCE.81.20

8. B.B. Khustalev, A.A. Moiseeva, Modern Economy: Problems and Solutions 6(2), 188198 (2012)

9. International standards ISO 14031:2013

10. B.B. Khustalev, A.A. Moiseeva, Competitiveness in the GlobalWorld: Economy, Science, Technology 7(2), 177-182 (2016)

11. B.B. Khustalev, Z.B. Pakhalina, M.E. Spirin, Competitiveness in the Global World: Economy, Science, Technology 8(3), 195-198 (2016)

12. P.G. Grabovyi, I.P. Avilova, Life science journal 12, 183-194 (2016)

13. A. Mottaeva, A. Zheltenkov, E3S Web of Conferences 33, 01038 (2018) doi: 10.1051/e3sconf/20183301038

14. C.E. Bolt-Lee, M. Swain, Journal of Accountancy December, 50-54 (2016)

15. W.G. Bremser, W.P. Wagner, The CPA Journal July, 62-67 (2013) 